\title{
EARNING MANAGEMENT MELALUI AKTIVITAS RIIL DAN AKRUAL
}

\author{
Suhesti Ningsih \\ STIE AAS Surakarta \\ Email : hestiningsih@gmail.com
}

\begin{abstract}
ABSTRAK
Earning Management (Manajemen laba) adalah perekayasaan laba yang dilakukan oleh manajer. Ada dua pendekatan dalam manajemen laba yaitu manajemen laba akrual dan manajemen laba riil. Manajemen laba akrual adalah perekayasaan laba melalui aktivitas akrual seperti metode akuntansi. Sedangkan manajemen riil adalah manipulasi laba melalui aktivitas-aktivitas riil. Manajemen laba akrual diukur dengan short term dan long term akrual diskresioner. Sedangkan manajemen laba riil diukur dengan arus kas operasi abnormal (abnormal $C F O$ ), biaya produksi abnormal (abnormal Production Costs), dan biaya diskresioner abnormal (abnormal Discretionary Expenses). Dari hasil beberapa penilitian menunjukan bahwa manajer lebih cenderung melakukan manajemen laba melalui aktivitas riil dibandingkan dengan aktivitas akrual karena dianggap dapat menangkap pengaruh riil lebih baik daripada hanya akrual operasi dan lebih sulit dideteksi oleh auditor daripada manajemen laba berbasis akrual.
\end{abstract}

\section{Kata Kunci : EarningManagement, Manajemen laba riil, Manajemen laba akrual}

\section{PENDAHULUAN}

Untuk melakukan investasi maupun memberikan kredit pada sebuah perusahaan, maka dibutuhkan informasi mengenai perusahaan tersebut sebagai dasar pertimbangan dalam pengambilan keputusan. Laporan Keuangan adalah merupakan salah satu bentuk informasi yang dibutuhkan oleh para pengambil keputusan, terutama bagi investor dan kreditor adalah laporan keuangan. Agar informasi keuangan bisa membuat para investor dan kreditor tertarik untuk melakukan investasi di perusahaan itu, maka kadangkala manajer perusahaan melakukan beberapa tindakan agar laporan keuangan perusahaan tampak bagus.

Dalam PSAK No. 1 disebutkan bahwa informasi laba diperlukan untuk menilai perubahan potensi sumber daya ekonomis yang mungkin dapat dikendalikan 
di masa depan, menghasilkan arus kas dari sumber daya yang ada dan untuk perumusan pertimbangan tentang efektivitas perusahaan dalam memanfaatkan tambahan sumber daya (IAI, 2010).

Menurut Scott (2009:403) earnings management sebagai pilihan yang dilakukan oleh manajer dalam menentukan kebijakan akuntansi yang dilakukan agar mempengaruhi laporan untuk mencapai beberapa tujuan tertentu. Manajemen laba (Earning Management) adalah perekayasaan laba yang dilakukan oleh manajer Manajemen laba berhubungan erat dengan tingkat perolehan laba (earning) atau prestasi suatu perusahaan. sehingga tidak mengherankan bila manajer sering berusaha menonjolkan prestasinya melalui tingkat keuntungan atau laba yang dicapai.

Perilaku manajemen laba selalu diasosiasikan dengan perilaku yang negative karena manajemen laba menyebabkan tampilan informasi keuangan tidak terceminkan keadaan yang sebenarnya. Hal ini terjadi akibat dari hubungan asimetri antara manajemen, pemegang saham dan pihak-pihak yang berkepentingan dengan tingkat kepentingan (keinginan) saling bersebrangan. Manajemen menginginkan bonus yang tinggi dengan meningkatkan laba perusahaan pada tahun yang bersangkutan. Sementara para pemegang saham, berusahan untuk menurunkan labanya dengan tujuan ingin menarik sahamnya kembali, dll.

Beberapa pendekatan dalam manajemen laba (Earning Management) yaitu manajemen laba dengan pendekatan riil (Real Earning Management) dan pendekatan akrual (Accrual Earning Management). Model pengukuran manajemen laba akrual ini oleh beberapa peneliti dianggap masih belum dapat mengungkapkan kondisi yang lengkap tentang praktik manajemen laba karena model tersebut mengabaikan hubungan antara transaksi arus kas dan akrual (Dechow et al. 1995, Guay et al. 1996, Kothari et al. 2005, Subramanyam 1996, Kothari 2001, Subekti, Wijayanti dan Akhmad 2010). Penelitian Roychowdhury (2006) menyimpulkan bahwa manajemen laba dengan hanya mendasarkan pada pengaturan akrual saja mungkin menjadi tidak valid. Hasil survey Graham, Harvey dan Rajgopal (2005) menemukan bukti kuat bahwa manajemen puncak sebagai responden jauh lebih bersedia untuk terlibat dalam manajemen laba riil (real earnings management) daripada manajemen akrual untuk mencapai target laba. Zang (2006) menunjukkan bahwa untuk mencapai target perusahaan menggunakan berbagai teknik manajemen laba, tidak hanya satu teknik saja.

Manajemen laba akrual diukur dengan jangka pendek (short term) dan jangka panjang (long term) akrual diskresioner. Sedangkan manajemen laba riil diukur dengan arus kas operasi abnormal (abnormal CFO), biaya produksi abnormal (abnormal Production Costs), dan biaya diskresioner abnormal (abnormal Discretionary Expenses). 


\section{TINJAUAN PUSTAKA}

\section{Teori Keagenan (Agency Theory)}

Untuk dapat memahami tentang manajemen laba maka perlu dipahami tentang hubungan keagenan. Dalam teori keagenan (agency theory) dijelaskan bahwa adanya asimetri informasi antara manajer sebagai agen dan pemilik (dalam hal ini adalah pemegang saham) sebagai prinsipal. Asimetri informasi muncul ketika manajer lebih mengetahui informasi internal dan prospek perusahaan di masa yang akan datang dibandingkan pemegang saham dan stakeholder lainnya.

Menurut Eisenhardt (1989) teori keagenan menggunakan tiga asumsi sifat manusia yaitu: (1) manusia pada umumya mementingkan diri sendiri (self interest), (2) manusia memiliki daya pikir terbatas mengenai persepsi masa mendatang (bounded rationality) dan (3) manusia selalu menghindari resiko (risk averse). Berdasarkan asumsi sifat dasar manusia tersebut manajer sebagai manusia akan bertindak opportunistic, yaitu mengutamakan kepentingan pribadinya. Sedangkan Jensen dan Meckling (1997) menyatakan bahwa hubungan keagenan adalah sebuah kontrak antara manajer (agent) dengan investor (principal).

Sebagai agen, manajer secara moral bertanggung jawab untuk mengoptimalkan keuntungan para pemilik (principal) dan sebagai imbalannya akan memperoleh kompensasi sesuai dengan kontrak. Dengan demikian terdapat dua kepentingan yang berbeda didalam perusahaan dimana masing-masing pihak berusaha untuk mencapai atau mempertahankan tingkat kemakmuran yang dikehendaki.
Menurut Scott (2000), terdapat dua macam asimetri informasi yaitu:

1. Adverse selection, yaitu bahwa para manajer serta orang-orang dalam lainnya biasanya mengetahui lebih banyak tentang keadaan dan prospek perusahaan dibandingkan investor pihak luar. Dan fakta yang mungkin dapat mempengaruhi keputusan yang akan diambil oleh pemegang saham tersebut tidak disampaikan informasinya kepada pemegang saham.

2. Moral hazard, yaitu bahwa kegiatan yang dilakukan oleh seorang manajer tidak seluruhnya diketahui oleh pemegang saham maupun pemberi pinjaman. Sehingga manajer dapat melakukan tindakan diluar pengetahuan pemegang saham yang melanggar kontrak dan sebenarnya secara etika atau norma mungkin tidak layak dilakukan.

Dalam kondisi yang asimetri tersebut, agent dapat mempengaruhi angkaangka akuntansi yang disajikan dalam laporan keuangan dengan cara melakukan manajemen laba (earning management). Sedang bagi pemilik modal akan sulit untuk mengontrol secara efektif tindakan manajemen. Praktek manajemen laba dapat dipandang dari dua perspektif yang berbeda, yaitu sebagai tindakan yang salah (negatif) dan tindakan yang seharusnya dilakukan manajemen (positif).

\section{Manajemen Laba (Earning Management)}

Menurut Healy dan Wahlen (1999) dalam Subekti dkk (2010) menyatakan manajemen laba terjadi ketika manajer 
menggunakan penilaian dalam pelaporan keuangan dan dalam penataan transaksi untuk mengubah laporan keuangan baik menyesatkan beberapa stakeholder tentang kinerja ekonomi yang mendasari perusahaan atau untuk mempengaruhi hasil kontraktual yang bergantung pada angka akuntansi yang dilaporkan.

$$
\text { Menurut Scott }
$$
mendefinisikan earnings management sebagai "the choice by a manager of accounting policies or actions affecting earnings so as to achieve some specific reported earnings objective". Dari definisi diatas maka earning management merupakan adanya pilihan yang dilakukan oleh manajer dalam menentukan kebijakan akuntansi yang dilakukan agar mempengaruhi laporan untuk mencapai beberapa tujuan tertentu. kebijakan dilakukan seperti pemilihan metode akuntansi dalam penyajian laporan keuangan, seperti menaikkan atau menurunkan angka laba yang dihasilkan perusahaan.

$$
\text { Scott }
$$$$
\text { (1997: }
$$
mengemukakan bentuk-bentuk manajemen laba yang dilakukan oleh manajer antara lain

\section{Taking a bath}

yaitu manajemen laba yang dilakukan ketika keadaan buruk yang tidak menguntungkan tidak bisa dihindari pada periode berjalan, dengan cara mengakui biaya-biaya pada periodeperiode yang akan datang dan kerugian periode berjalan.

\section{Income minimization}

Manajemen laba dilakukan pada saat perusahaan memperoleh profitabilitas yang tinggi agar tidak mendapat perhatian secara politis. Kebijakan yang diambil bisa berupa pembebanan pengeluaran iklan, riset dan pengembangan yang cepat dan sebagainya.

3. Income maximization

Yaitu memaksimalkan laba dengan tujuan memeroleh bonus yang lebih besar. Demikian pula dengan perusahaan yang mendekati suatu pelanggaran kontrak hutang jangka panjang, manajer perusahaan tersebut akan cenderung untuk memaksimalkan laba.

4. Income smoothing

Melalui income smoothing, manajer menaikkan atau menurunkan laba untuk mengurangi fluktuasi laba yang dilaporkan sehingga perusahaan terlihat stabil dan tidak beresiko tinggi.

Teori akuntansi positif (Positif Accounting Theory) mengusulkan tiga hipotesis motivasi manajemen laba, yaitu: (1) hipotesis program bonus (the bonus plan hypotesis), (2) hipotesis perjanjian hutang (the debt covenant hypotesis) dan (3) hipotesis biaya politik (the political cost hypotesis) (Watts dan Zimmerman, 1986).

\section{Manajemen Laba Akrual (Accrual Earning Management)}

Manajemen laba akrual adalah merupakan salah satu teknik pengelolaan laba yang biasa digunakan. Manajemen laba akrual ditunjukkan dengan adanya discretionary accrual (diskresioner akrual). Penggunaan diskresioner akrual digunakan JURNAL AKUNTANSI DAN PAJAK VOL. 16 NO. 01, JULI 2015 - 58 
untuk menjadikan laporan keuangan lebih informatif yaitu laporan keuangan yang dapat mencerminkan keadaan yang sesungguhnya.

Pemisahan discretionary accrual menjadi short term dan long term discretionary accrual dilakukan oleh Whelan dan McNamara (2004) berdasarkan model Jones (1991).Penggunaan short term accruals ditujukan untuk lebih mengurangi masalah timing dan matching. Sementara itu, tidak terdapat kejelasan alasan penggunaan long term accruals untuk mengakomodasi tujuan tersebut. Hal ini dikarenakan penggunaan long term accruas dipengaruhi oleh proses politis (Watts dan Zimmerman, 1989).

Selanjutnya Whelan dan McNamara (2004) menyatakan bahwa pasar mungkin akan menganggap penggunaan long term discretionary accruals adalah usaha manajer untuk membodohi pelaku pasar, karena sifat dari akrual tersebut yang memberikan kesempatan bagi manajer untuk melakukan manipulasi

\section{Manajemen Laba melalui aktivitas riil (Real Earning Management)}

Teknik manajemen laba dengan memanipulasi aktivitas aktivitas riil (manajemen laba riil) diperkenalkan oleh Roychowdhury (2006) mendefinisikan manajemen laba riil sebagai berikut "management actions that deviate from normal business practice, undertaken with the primary objective of meetings certain earnings thresholds.". Hal ini berarti manajemen laba riil adalah tindakantindakan manajemen yang menyimpang dari praktek bisnis yang normal yang dilakukan dengan tujuan utama untuk mencapai target laba. Manipulasi aktivitas riil seperti memberi diskon harga, penurunan beban diskresioner serta prosuksi dalam jumlah yang besar.

Konsisten dengan definisi Roychowdhury (2006), Graham et all (2005) menemukan bahwa (a) eksekutif keuangan memberikan perhatian yang besar terhadap target laba seperti laba nol (zero earning), laba periode sebelumnya dan ramalan analis; (b) mereka akan melakkan manipulasi aktivitas riil untuk mencapai target ini, meskipun tindakan pengelolaan ini secara potensial mengurangi nilai perusahaan.

Dalam mendeteksi manajemen laba riil yang dilakukan oleh perusahaan, Roychowdhury, 2006; Cohen dan Zarowin, 2010). manajemen laba riil dapat dilakukan dengan 3 (tiga) cara yaitu:

a. Manipulasi Penjualan

Manipulasi penjualan merupakan usaha manajemen dalam meningkatkan penjualan secara temporer dalam periode tertentu dengan menawarkan diskon harga, produk secara berlebihan atau memberikan persyaratan kredit yang lebih lunak. Strategi ini dapat meningkatkan volume penjualan dan secara tidak langsung akan meningkatkan laba dan aliran kas periode saat ini.

b. Mengurangi beban-beban diskresionari (dicretionary expenditures)

Perusahaan dapat menurunkan discretionary expenditures seperti beban penelitian dan pengembangan, iklan, penjualan, adminstrasi dan umum terutama dalam periode di mana pengeluaran tersebut tidak langsung 
menyebabkan pendapatan dan laba. Strategi ini dapat meningkatkan laba dan arus kas periode saat ini namun memiliki efek positif terhadap arus kas.

c. Produksi yang berlebihan (overproduction)

Untuk meningkatkan laba, manajer perusahaan dapat memproduksi lebih banyak daripada yang diperlukan karena tingkat produksi yang lebih tinggi akan menyebabkan biaya tetap per unit produk lebih rendah. Strategi ini dapat menurunkan kos barang terjual (cost of goods sold) dan meningkatkan laba.

Dengan ketiga cara di atas perusahaan-perusahaan yang diduga (suspect) melakukan manipulasi aktivitas riil akan mempunyai abnormal cash flow operations (CFO) dan abnormal production cost yang lebih besar dibandingkan perusahaan-perusahaan lain serta abnormal discretionary expenses yang lebih kecil.

Hasil survey yang dilakukan oleh Graham et al. (2005), Roychowdhury (2006) menunjukkan para eksekutif keuangan cenderung lebih memilih memanipulasi laba melalui aktivitas-aktivitas riil daripada aktivitas akrual. Hal ini disebabkan oleh:

1. Manipulasi akrual cenderung membuat para audior atau regulator melakukan pemeriksaan dengan cepat daripada jika keputusan-keputusan tentang aktivitas

a. Menghitung besarnya total akrual ACCi,t = EARNi,t - CFOi,t

b. Menghitung besarnya short term accrual STACCi,t = ?ARi,t+?INVi,t+?OCAi,t-?APi,t-?TXPi,t-?OCLi,t .......(2)

c. Menghitung besarnya long term accrual

LTACCi,t = ACCi,t - STACCi,t

$d$. Menghitung besarnya short term discretionary accrual 


$$
\mathrm{STDA}=\frac{\text { STACCi,t }}{\mathrm{TAi}, \mathrm{t}-1}-\left\{\beta 1\left(\frac{1}{\log T A \mathrm{i}, \mathrm{t}-1}\right)+\beta 2\left(\frac{\Delta \mathrm{REVi}, \mathrm{t}-\Delta \mathrm{RECi}, \mathrm{t}}{\mathrm{TAi}, \mathrm{t}-1}\right)+\beta 3\left(\frac{\text { INCi, }, \mathrm{t}}{\mathrm{TAi}, \mathrm{t}-1}\right)\right\}
$$

Dimana :

$\mathrm{STDA}_{\mathrm{i}, \mathrm{t}}=$ Jangka pendek akrual diskresioner cocok kinerja

STACC $_{\mathrm{j}, \mathrm{t}}=$ Jangka pendek akrual untuk perusahaan I dalam tahun $\mathrm{t}$

$\mathrm{TA}_{\mathrm{j}, \mathrm{t}-1}=$ Total aset untuk perusahaan i pada akhir tahun $\mathrm{t}-1$

Log. $\mathrm{TA}_{\mathrm{j}, \mathrm{t}-1}=$ Logaritma dari jumlah aktiva untuk perusahaan i pada akhir tahun $\mathrm{t}-1$

$\triangle \mathrm{REV}_{\mathrm{j}, \mathrm{t}}=$ Pendapatan tahun $\mathrm{t}$ pendapatan kurang dalam tahun $\mathrm{t}-1$ untuk perusahaan $\mathrm{i}$

$\triangle \mathrm{REC}_{\mathrm{j}, \mathrm{t}}=$ Jumlah piutang usaha dalam tahun t piutang kurang dalam tahun $\mathrm{t}-1$ untuk

perusahaan $\mathrm{i}$

$\mathrm{INC}_{\mathrm{it}}=$ Laba Bersih pada tahun $\mathrm{t}$ untuk perusahaan $\mathrm{i}$

2. Long term discretionary accrual (LTDA)

LTDA adalah penyimpangana ntara aktual jangka panjang masih harus dibayar dan

$$
\text { LTDA }=\frac{\text { LTACCi,t }}{\text { TAi, }-1} \cdot\left\{\beta 1\left(\frac{1}{\text { Log TAi,t-1 }}\right)+\beta 2\left(\frac{\text { PPEi, },}{\text { TAi,t-1 }}\right)+\beta 3\left(\frac{\text { INTi,t }}{\text { TAi,t-1 }}\right)+\beta 4\left(\frac{\text { INCi,t }}{\text { TAi,t-1 }}\right)\right\}
$$

dimana:

LTDA $_{\mathrm{it}}=$ jangka panjang akrual diskresioner kinerja

$\mathrm{LTACC}_{\mathrm{j}, \mathrm{t}}=$ jangka panjang akrual untuk perusahaan i pada tahun $\mathrm{t}$

TAI, $\mathrm{t}-\mathrm{l}=$ Total aset untuk perusahaan i pada tahun $\mathrm{t}-1$

Log. $\mathrm{TA}_{\mathrm{i}, \mathrm{t}-1}=$ Logaritma dari jumlah aktiva untuk perusahaan i pada tahun $\mathrm{t}^{-1}$

PPEi, ${ }_{\mathrm{t}}=$ Aktiva dan peralatan untuk perusahaan i pada akhir tahun $\mathrm{t}$

$\mathrm{INT}_{\mathrm{J}, \mathrm{t}}=$ Berwujud aset untuk perusahaan i pada akhir tahun $\mathrm{t}$

$\mathrm{INC}_{\mathrm{i}, \mathrm{t}}=$ Laba Bersih untuk perusahaan i pada akhir tahun

\section{Pengukuran Manajemen Laba Riil}

Konsep pengukuran manajemen laba riil menggunakan 3 proksi yaitu abnormal cash flow operations abnormal production costs, dan abnormal discretionary expenses (Roychowdhury;2006).

1. Abnormal cash flow operations

(Abnormal CFO) / Arus kas operasi abnormal.
Abnormal CFO adalah manipulasi laba yang dilakukan perusahaan melalui aliran operasi kas yang akan memiliki aliran kas lebih rendah daripada level normalnya. Formulanya sebagai berikut : 


$$
\mathrm{CFO}_{t} / A_{t-1}=\alpha_{0}+\alpha_{1}\left(1 / \log \cdot A_{t-1}\right)+\beta_{1}\left(S_{t} / A_{t-1}\right)+\beta_{2}\left(\Delta S_{t} / A_{t-1}\right)+\varepsilon_{t}
$$

2. Abnormal production cost (Abnormal $P R O D)$ / Biaya kegiatan produksi abnormal.

Abnormal PROD adalah Manajemen laba riil yang dilakukan melalui manipulasi biaya produksi, dimana perusahaan akan memiliki biaya produksi lebih tinggi daripada level normalnya. Formulanya sebagai berikut:

$$
\operatorname{PROD}_{t} / A_{t-1}=\alpha_{0}+\alpha_{1}\left(1 / \log . A_{t-1}\right)+\beta_{1}\left(S_{t} / A_{t-1}\right)+\beta_{2}\left(\Delta S_{t} / A_{t-1}\right)+\beta_{3}\left(\Delta S_{t-1} / A_{t-1}\right)+\varepsilon_{t}
$$

3. Abnormal discretionary expenses (Abnormal DISC) /Biaya diskresionari abnormal.

dan pengembangan, biaya iklan, biaya penjualan, administrasi, dan umum. Formula untuk Abnormal DISC:

Abnormal DISC adalah manipulasi laba yang dilakukan melalui biaya penelitian

$$
\operatorname{DISC}_{t} / A_{t-1}=\alpha_{0}+\alpha_{1}\left(1 / \log . A_{t-1}\right)+\beta\left(\Delta S_{t-1} / A_{t-1}\right)+\varepsilon_{t}
$$

dimana:

$\mathrm{CFO}_{\mathrm{t}}=$ arus kas operasi perusahaan i pada tahun $\mathrm{t}$

$\mathrm{PROD}_{\mathrm{t}}=$ harga pokok penjualan ditambah perubahan persediaan .

DISC $_{t}=$ biaya penelitian dan pengembangan ditambah biaya iklan ditambah biaya penjualan, administrasi, dan umum.

$\mathrm{A}_{\mathrm{t}-1}=$ Total aset perusahaan pada akhir tahun $\mathrm{t}-1$

$\mathrm{S}_{\mathrm{t}}=$ Penjualan perusahaan pada akhir tahun $\mathrm{t}$

$\Delta \mathrm{S}_{\mathrm{t}}=$ Perubahan penjualan perusahaan pada tahun $\mathrm{t}$ dibandingkan dengan penjualan pada akhir tahun $\mathrm{t}_{-1}$

$\Delta \mathrm{S}_{\mathrm{t}-1}=$ Perubahan penjualan perusahaan pada tahun $\mathrm{t}_{-1}$ dibandingkan dengan penjualan pada akhir tahun $\mathrm{t}_{-2}$

$\alpha, \beta=$ Koefisien regresi

$\varepsilon_{\mathrm{t}}=$ error

Kegiatan riil operasi dianggap dapat menangkap pengaruh riil lebih baik daripada hanya akrual operasi. Indikasi keterlibatan manajemen perusahaan pendapatan dengan manipulasi aktivitas riil dapat ditunjukkan oleh nilai abnormal kegiatan. Pengukuran nilai abnormal dari aktivitas setiap deviasi antara nilai aktual dan nilai aktivitas aktivitas yang diharapkan.

Penelitian-Penelitian Earning Management 
Penelitian mengenai manajemen laba telah banyak dilakukan sebelumnya dengan berbagai alternatif metode pendekatan. Zayene et al (2010) dalam penelitiannya menguji nilai relevansi short term discretionary accrual dan long term discretionary accrual di hadapan IOS (Investment Opportunity Set) yang menunjukkan investasi perusahaan / opsi pertumbuhan perusahaan. Hasil empiris menunjukkan bahwa short term discretionary accrual dan long term discretionary accrual tidak memberikan informasi yang sama ke pasar modal.

Penelitian yang telah dilakukan Fauziah (2011) menunjukkan bahwa trend earnings management tidak memberikan pola yang sama dari tahun ke tahun. Namun secara keseluruhan dari total rata-rata earnings management dihasilkan nilai positip.

(2012) dengan pendekatan long term discretionary accrual dan short term discretionary accrual bahwa praktik manajemen laba dengan model long term discretionary accrual cenderung menggunakan pola menaikkan angka laba dengan cara mempengaruhi komponen komponen aktiva tetap. Sedangkan model short term discretionary accrual cenderung menggunakan pola menurunkan angka laba dengan cara mempengaruhi komponen komponen aktiva lancar.

Roychowdhury (2006) memberikan bukti empiris bahwa perusahaan melakukan manajemen laba riil untuk menghindari pelaporan kerugian. Konsisten dengan Cohen et al. (2008) menunjukkan bahwa manajemen laba berbasis akrual yang dilakukan perusahaan meningkat sebelum periode SOX dan menurun setelahnya. Sebaliknya, manajemen laba riil menurun sebelum SOX dan meningkat secara signifikan setelahnya. Hal ini menunjukkan bahwa strategi perusahaan mencapai target laba telah beralih dari strategi manajemen laba berbasis akrual ke manajemen laba riil

Sedangkan Ferdawati (2009) secara empiris membuktikan bahwa manajemen laba riil mempunyai pengaruh positif terhadap nilai perusahaan. Dan nilai perusahaan yang melakukan manajemen laba riil lebih rendah dari nilai perusahaan yang tidak melakukan manajemen laba riil, walaupun laba perusahaan sama-sama menlngkat.

Ratmono (2010) yang meneliti tentang kemampuan auditor mendeteksi manajemen laba riil dan akrual. Hasil penelitian ini sejalan dengan dugaan Roychowdhury (2006) serta Cohen dan Zarowin (2010), manajemen laba riil lebih sulit dideteksi oleh auditor daripada manajemen laba berbasis akrual.

Penelitian yang dilakukan oleh Hastuti (2011) yang meneliti tentang titik kritis manajemen laba pada perubahan tahap life cycle perusahaan, analisis manajemen laba riil dibandingkan dengan manajemen laba akrual. Hasil penelitian menunjukkan bahwa 
perusahaan-perusahaan yang berada pada titik kritis growth-mature dan mature-stagnant memilih discretionary accrual yang menaikkan laba. Selain itu, perusahaanperusahaan yang berada pada titik kritis growth-mature dan mature-stagnant lebih cenderung melakukan manajemen laba riil dibandingkan manajemen laba akrual.

Fazeli dan Rasouli (2011), peneliti dari Iran meneliti tentang manajemen laba riil dan relevansi nilai laba dengan hasil relevansi nilai laba yang dilaporkan adalah secara signifikan lebih rendah dari manajemen laba.

Penelitian Trisnawati dan Ningsih (2012) tentang praktik manajemen laba riil studi komparasi pada perusahaan yang listing di indeks LQ 45 dan JII menunjukan bahwa dalam kurun waktu 2004-2010 perusahaan-perusahaan yang pada kedua indeks melakukan manajemen laba.

\section{KESIMPULAN}

Manipulasi laba yang dilakukan oleh manajer disebut manajemen laba (earning management). Ada dua pendekatan dalam manajemen laba yaitu manajemen laba akrual (accrual earning management) dan manajemen laba riil (real earning management). Manajemen laba akrual adalah Manajemen laba akrual adalah pengelolaan laba berdasarkan pada proksi akrual diskresionari (discretionary accruals). Manajemen laba akrual dapat dilakukan dengan merekayasa metode akuntansi yang digunakan. sedangkan pengukurannya ada dua yaitu short-term discretionary accruals dan long-term discretionary accruals

Sedangkan manajemen laba riil (real earning management) adalah perekayasaan laba yang dilakukan melalui manipulasi aktivitas-aktivitas riil perusahaan. Berdasarkan konsep yang dikembangkan oleh Roychowdhury (2006) pengukuran manajemen laba riil menggunakan 3 proksi yaitu abnormal cash flow operations (Abn. CFO), abnormal production costs Abn. PROD), dan abnormal discretionary expenses (abn DISCR). Nilai abnormal diukur dari aktivitas aktivitas setiap deviasi antara nilai aktual dan nilai aktivitas aktivitas yang diharapkan.

Dari hasil penelitian-penelitian yang dilakukan menunjukkan bahwa manajer lebih cenderung memilih melakukan manajemen laba dengan manipulasi aktivitas riil kegiatan riil operasi dianggap dapat menangkap pengaruh riil lebih baik daripada hanya akrual operasi. Disamping itu manajemen riil lebih sulit dideteksi oleh auditor. Hal ini tidak saja terjadi pada perusahaan-perusahaan di Indonesia tetapi juga perusahaan-perusahaan di negara lain.

\section{DAFTAR PUSTAKA}

Ahmad Z, Subekti I, dan Kee PL,. (2010). The effect of integrated earnings management on the value Relevance of earnings and book value of equity. 
Cohen, Daniel A. dan Paul Zarowin. 2010. Accrual-Based and Real Earnings Management Activities Around Seasoned Equity Offerings. Journal of Accounting \& Economics Vol. 50 No. 1: 2-19.

Eisenhardt, Kathleem. M. (1989). Agency Theory: An Assesment and Review. Academy of management Review, 14, hal 57-74

Fischer, M. dan K. Rosennveig (1995). Attitudes of Shidents and Accounting Practitioners concerning the Ethical Acceptability of Eamings Management. Journal of Business Ethics, Vol. 14, No. 6, hlm. 43344.

Fazeli Y. S. and Rasouli H.A.. 2011 Real Earnings Management and the Value Relevance of Earnings. International Research Journal of Finance and Economics ISSN 14502887 Issue 62 (2011) (C) EuroJournals Publishing, Inc. 2011.

Ferdawati. 2009. Pengaruh Manajemen Laba Riil terhadap Nilai Perusahaan. Jurnal Akuntansi \& Manajemen Vol 4 No.1 Juni 2009 ISSN 1858-3687 hal 59-74

Graham, J. R., Harvey, C. R., \& Rajgopal, S. (2005). The Economics Implications of Corporate Financial Reporting. Journal of Accounting and Economics, 40 (1-3), 3-73.
Gunny, K. 2005. What are The Consequences of Real Earnings Manajement? Working Paper. University of Colorado.

Hastuti, Sri. 2011.Titik Kritis Manajemen Laba Pada Perubahan Tahap Life Cycle Perusahaan: Analisis Manajemen Laba Riil Dibandingkan Dengan Manajemen Laba Akrual. Simposium Nasional Akuntansi XIV. Banda Aceh.

Ikatan Akuntan Indonesia, (2010). Pernyataan Standar Akuntansi Keuangan No. 7. Pengungkapan Pihak-pihak yang Mempunyai Hubungan Istimewa.

Jensen, J.M. \& Meckling, W.H (1999) Theory of The Firm: Managerial Behavior,Agency Costs And Ownership Structure. Journal of Financial Economics, October, 1976, V. 3, No. 4, pp. 305-360,

Ratmono, Dwi. 2010. Manajemen Laba Riil dan Berbasis Akrual: Dapatkah Auditor yang Berkualitas Mendeteksinya?. Proceeding Simposium Nasional Akuntansi XIII, Purwokerto.

Roychowdhury, Sugata. (2006). Earnings Management through Real Activities Manipulation. Journal of Accounting and Economic, 42, 335370.

Trisnawati,Rina dan Ningsih, Suhesti (2012), Riil Earnings Management Practices: The Comparative Studies Between 


Shariah Index And Conventional
Index In Indonesian Stock Exchange
during 2004-2010 period, paper
accepted on Malaysia-Indonesia
International Conference in Economics,
Management and Accounting(
MIICEMA), October 18th-20th
,Palembang Indonesia

Scott, William R, 2000, Financial Accounting Theory Second edition. Canada Prentice Hall.
Wiyadi dan Safitri, LA (2012), Accrual Earnings Management Practices: Studies Empiric Conventional Index In Indonesian Stock Exchange during 2004-2010 period, paper accepted on Malaysia-Indonesia International Conference in Economics, Management and Accounting( MIICEMA), October 18th-20th, Palembang Indonesia 